\title{
Impregnation processes of insulation rigid components of cellulose in synthetic ester and mineral oil
}

\author{
Alfredo Ortiz \\ Electrical and Energy Engineering Dep. \\ University of Cantabria \\ Santander, Spain \\ ortizfa@unican.es \\ Cristina Fernández-Diego \\ Electrical and Energy Engineering Dep. \\ University of Cantabria \\ Santander, Spain \\ fdezdiegoc@unican.es
}

\author{
Jaime Sanz \\ Electrical and Energy Engineering Dep. \\ University of Cantabria \\ Santander, Spain \\ jaimesa85@gmail.com \\ Ernesto Iván Diestre \\ Repsol Technology Center \\ Móstoles, Spain \\ ediestrer@repsol.com
}

\author{
Severiano Pérez \\ Electrical and Energy Engineering Dep. \\ University of Cantabria \\ Santander, Spain \\ severiano.perez@unican.es \\ Ismael Vela \\ Repsol Technology Center \\ Móstoles, Spain \\ isvelamor@repsol.com
}

\begin{abstract}
Although oil-immersed power transformers generally use mineral oil as insulation and cooling fluid, this liquid does not meet the new technical requirements of dielectric fluids such as high biodegradability, non-toxicity and high safety. For these reasons, natural and synthetic esters as alternative to mineral oil have increased their utilization in some transformers installations. Despite the fact that there are several works that have demonstrated the suitability of these insulation fluids from the point of view of their stability, dielectric and thermal properties, there are very few works focused on the study of the effects of these liquids on impregnation process. The aim of this work is provide information about the behavior of different rigid insulation materials, not studied until now, during the impregnation process in a synthetic ester compared with a mineral oil.
\end{abstract}

Keywords- impregnation, mineral oil, synthetic ester, power transformer, insulation, cellulose.

\section{INTRODUCTION}

Transformers are devices of critical importance in current electric power transmission and distribution [1]. The reliability of these machines depends on their insulation system [2] which usually consists of paper-impregnated insulation [3] and mineral oil. This liquid has been used for decades due to its suitable insulating properties, low viscosity and cost [4]. However, this insulation fluid has relatively low flash and fire points, it is also toxic in nature, and hazardous in the soil and in the water [5], being its biodegradability not more than $30 \%$ [6]. Consequently, mineral oil has started to be substituted specially in distribution transformers for alternative liquids such as natural and synthetic esters mainly due to its biodegradability and fire safety properties $[7,8]$.

There is a great deal of works which have analyzed different issues related with the use of new insulation liquids in power transformer such as ageing behavior [3, 5, 7, 9-10], dielectric [11-12] or thermal properties [2, 13]. Although thermal and dielectric properties, as well as stability of new fluids are critical to guarantee transformers' performance during operation, the effects of the use of natural and synthetic esters on manufacturing process are not less important. During this process it is required the complete impregnation of

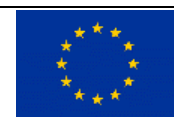

This project has received funding from the European Union's Horizon 2020 research and innovation programme under the Marie Sklodowska-Curie grant agreement No 823969BIOTRAFO insulation solid components, previously dried [14], with the dielectric oil to assure the level of partial discharges does not exceed the levels marked by the IEC standard [15]. Due to physical differences between alternative oils and mineral oil much longer time might be needed to achieve impregnation of the cellulosic rigid materials, used in insulation systems of power transformers. This critical process was modeled and validated for the first time by Dufour and Molinari in 1975 [16]. They studied this phenomenon through the measure of breakdown voltage in pressboard that was impregnated by mineral oil. Additionally, they studied the effect of temperature on the impregnation time. Subsequently, in 1984 researchers from Toshiba Corporation also studied the impregnation of transformer board in mineral oil $[17,18]$. They obtained in their first work that temperature and vacuum level increase have a positive effect on impregnation rate. In their second work, these authors used their experimental results to develop the equations that allowed to describe the impregnation process. This theoretical study included the capillarity as a variable which influences on impregnation process unlike Dufour and Molinari did [16]. Board impregnation in mineral oil was also carried out by Krause et al. [19]. However, their aim was evaluate the impact of drying, impregnation and temperature cycles on the clamping tension of transformers windings. It was not until 2007 that the impregnation processes of insulation solids with alternative liquids was considered. Dai and Wang studied impregnation behavior of different cellulosic solids (paper, pressboard and laminated pressboard blocks) used as insulation solids [20, 21]. These authors compared the impregnation in a mineral oil, a natural and a synthetic ester. They found that the time needed in this process is a function of viscosity and capillary effect of the oil inside cellulosic materials. Similar conclusions were found by $\mathrm{Lu}$ et al. [22] who evaluated impregnation process of pressboard in mineral and rapeseed oil.

As it has been shown above, there are few studies focused on impregnation process. Furthermore, the type of solid materials in which this phenomenon has been observed does not include other important components [23] used in transformers' manufacture. For this reason, the authors of this 
work have studied the impregnation rate in seven different components of the solid insulation system commonly used in power transformers. Two different types of liquids have been considered: a mineral oil and a synthetic ester both of which have not been previously studied. This experimental work not only evaluates the behavior of laminated pressboard blocks that have already been studied, but also other kind of rigid materials such as phenolic wood blocks, laminated pressboard sheets, strips and spacers.

\section{OIL'S VISCOSITY}

Viscosity describes an internal friction that real fluids have when they flow. This property is a friction force between different layers of the fluid with different velocities and in liquids is originated by the intermolecular forces [24]. There are two quantities that are called viscosity: the dynamic viscosity and the kinematic viscosity. The latter is the ratio of the dynamic viscosity of a fluid to its density. Kinematic viscosity is a measure of the resistive flow of a fluid under the influence of gravity. The more viscous a fluid is, the slower flow speed inside the channels will be. Therefore, it is preferred an oil with low viscosity during impregnation. As one of the fundamental physical properties of liquids, it has been demonstrated that temperature and pressure are the only parameters that change viscosity's magnitude [24]. This is especially interesting when high viscous oils, as natural and synthetic esters, are used. In Table I is shown the kinematic viscosities of the two different oils evaluated in this work. These data have been obtained from the data sheets published by the manufacturer. It can be observed that a high temperature reduces the viscosity of the oil and hence shortens the impregnation time.

TABLE I. KINEMATIC VISCOSITIES VS TEMPERATURE

\begin{tabular}{|c|c|c|}
\hline \multirow{2}{*}{ Temperature $\left({ }^{\circ} \mathbf{C}\right)$} & \multicolumn{2}{|c|}{ Kinematic viscosity $\left(\mathbf{m m}^{2} / \mathbf{s}\right)$} \\
\cline { 2 - 3 } & Mineral oil & Synthetic ester \\
\hline-30 & 1800 & 3000 \\
\hline-20 & & 35 \\
\hline 40 & 12 & \\
\hline 100 & 3 & \\
\hline
\end{tabular}

\section{CAPILLARITY}

The capillary effect can be described as the elevation of fluids through a thin tube, a cylinder or a permeable substance. This phenomenon is caused because the interfacial energy of the solid-liquid interface is appreciably lower than that of the solid-vapor interface. This leads to a free surface energy reduction on wetting the solid walls of the capillary tube that is balanced by the gain in gravitational potential energy represented by the capillary rise [25]. In order to know the amount of liquid that can be elevated by capillary action, it is also necessary to consider the diameter of the container and the gravitational forces. When there is no added pressure difference, the movement of the oil within the dielectric paper will be based solely on the capillary action. In this way, the impregnation length can be determined by the following expression [21]:

$$
L=\sqrt{\frac{r T \cos \theta}{2 \eta}} \sqrt{t}
$$

$\mathrm{L}=$ Depth of impregnation (m)

$\mathrm{r}=$ Equivalent radius of capillary $(\mathrm{m})$
$\mathrm{T}=$ Surface tension of the oil $(\mathrm{N} / \mathrm{m})$

$\theta=$ Contact angle between oil and cellulose $\left(^{\circ}\right)$

$\eta=$ Dynamic viscosity (Pa s)

$\mathrm{t}=$ Impregnation time $(\mathrm{s})$

As it can be seen, there is a linear relationship between the depth of the impregnation and the square root of impregnation time.

\section{IMPREGNATION EXPERIMENTS}

This work has analysed the behaviour of different rigid insulation materials, during the impregnation process at $70^{\circ} \mathrm{C}$ in a synthetic ester compared with a mineral oil.

\section{A. Experimental setup}

The tests were carried out to compare the capillary action of mineral oil to synthetic ester in the structure of seven different rigid insulation materials. The rigid insulation materials were vertically placed upon the oil samples with the bottoms immersed in the oil, as it is shown in Fig. 1.

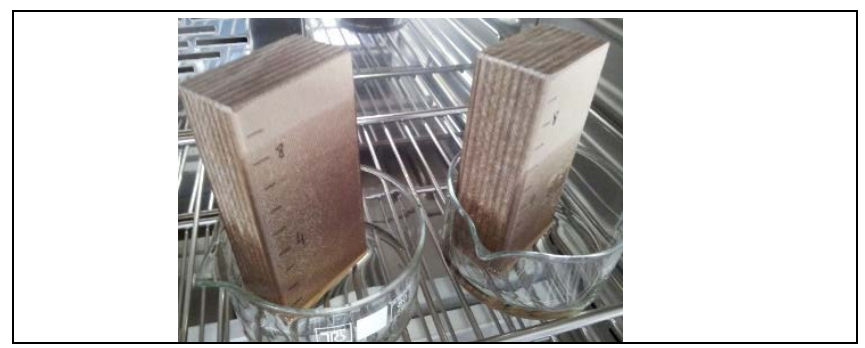

Fig. 1. Experimental setup of capillary tests.

The rising height of the oil in studied materials was monitored by observing the colour of the materials. The oil impregnation was measured under several periods of time and different samples were tested in order to give average values. To reduce the effect of the oil viscosity on impregnation speed, tests were done at $70^{\circ} \mathrm{C}$. This temperature will provide data of the highest impregnation rate which could be obtained without reduce excessively (less than 10\%) the mechanical properties of the studied materials during impregnation process. Increasing the impregnation temperature above $70^{\circ} \mathrm{C}$ could have had a negative effect on the mechanical strength of the studied dielectric materials.

\section{B. Analysed samples}

A type of conventional mineral insulating oil (Repsol Electra $3^{\mathrm{TM}}$ ) and a synthetic ester insulating oil (Repsol Bio Electra Synth ${ }^{\mathrm{TM}}$ ) were compared in this study. The properties of both oils are gathered in Table II.

TABLE II. PROPERTIES OF THE DIELECTRIC OILS

\begin{tabular}{|l|c|c|c|}
\hline \multicolumn{1}{|c|}{ Property } & Units & Mineral oil & $\begin{array}{c}\text { Synthetic } \\
\text { ester }\end{array}$ \\
\hline $\begin{array}{l}\text { Density at } 20^{\circ} \mathrm{C} \mathrm{(ISO} \\
\text { 12185) }\end{array}$ & $\mathrm{g} / \mathrm{cm}^{3}$ & 0.84 & 0.969 \\
\hline Pour point (ASTM D97) & ${ }^{\circ} \mathrm{C}$ & -48 & -50 \\
\hline $\begin{array}{l}\text { Total acidity (IEC } \\
62021-2)\end{array}$ & $\mathrm{mg} \mathrm{KOH/g}$ & $<0.001$ & 0.01 \\
\hline $\begin{array}{l}\text { Dielectric loss factor at } \\
90^{\circ} \mathrm{C} \text { (IEC 60247) }\end{array}$ & & 0.00074 & 0.005 \\
\hline $\begin{array}{l}\text { Dielectric breakdown } \\
\text { voltage (IEC 60156) }\end{array}$ & $\mathrm{kV}$ & 35 & \\
\hline Untreated & $\mathrm{kV}$ & $>70$ & 77 \\
\hline Treated & & & \\
\hline
\end{tabular}


The rigid insulation materials that have been studied are showed in Fig. 2.

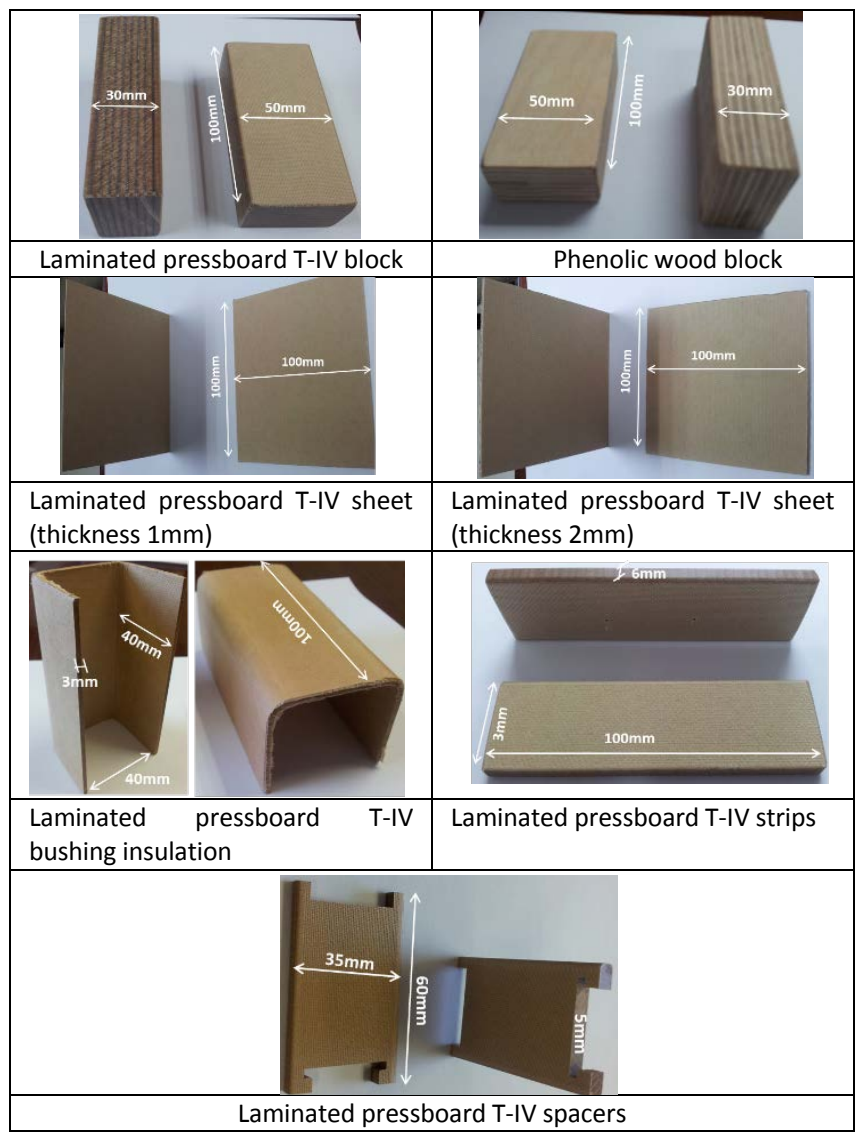

Fig. 2. Samples of rigid cellulosic components.

\section{IMPREGNATION RESULTS}

The movement of synthetic ester in laminated pressboard TIV block at $70^{\circ} \mathrm{C}$ in comparison with mineral oil is showed in Fig. 3. The obtained results fit a straight relationship between impregnation depth of oils in rigid insulation materials and the square root of impregnation time. The slopes of oil height against square root of time are gathered in Table III. In blocks and strips have been distinguished the impregnation speed of frontal and sideway because in some of them there is a considerable difference.

At a raised temperature $\left(70^{\circ} \mathrm{C}\right)$ the impregnation depth is higher in mineral oil compared with synthetic ester for the seven rigid materials. If the impregnation times are compared, it can be established for the mineral oil that it is needed around 5, 4, 2.8, 3.2, 28, 15 and 1 hours to get an impregnation height of $5 \mathrm{~cm}$ in the laminated pressboard TIV block, laminated pressboard T-IV bushing insulation, laminated pressboard T-IV sheet (thickness $1 \mathrm{~mm}$ ), laminated press-board T-IV sheet (thickness $2 \mathrm{~mm}$ ), laminated pressboard T-IV spacers, laminated pressboard T-IV strips and phenolic wood block, respectively. On the other hand, when the impregnation is carried out in the synthetic ester, are required around 12, 7, 7, 10, 43, 45 and 2.4 hours. In both dielectric liquids, mineral and synthetic ester, the maximum impregnation rate corresponds to the phenolic wood block. However, the minimum impregnation is different in both fluids, in the case of mineral oil the lowest rate is found in laminated pressboard T-IV spacers whereas in the synthetic ester is obtained in the strips. If maximum and minimum rates found in mineral oil are compared, it is obtained that the phenolic wood block impregnates about forty times faster than laminated press-board T-IV spacers, while in the synthetic ester the wood block impregnates around nineteen times quicker than laminated pressboard T-IV strips.

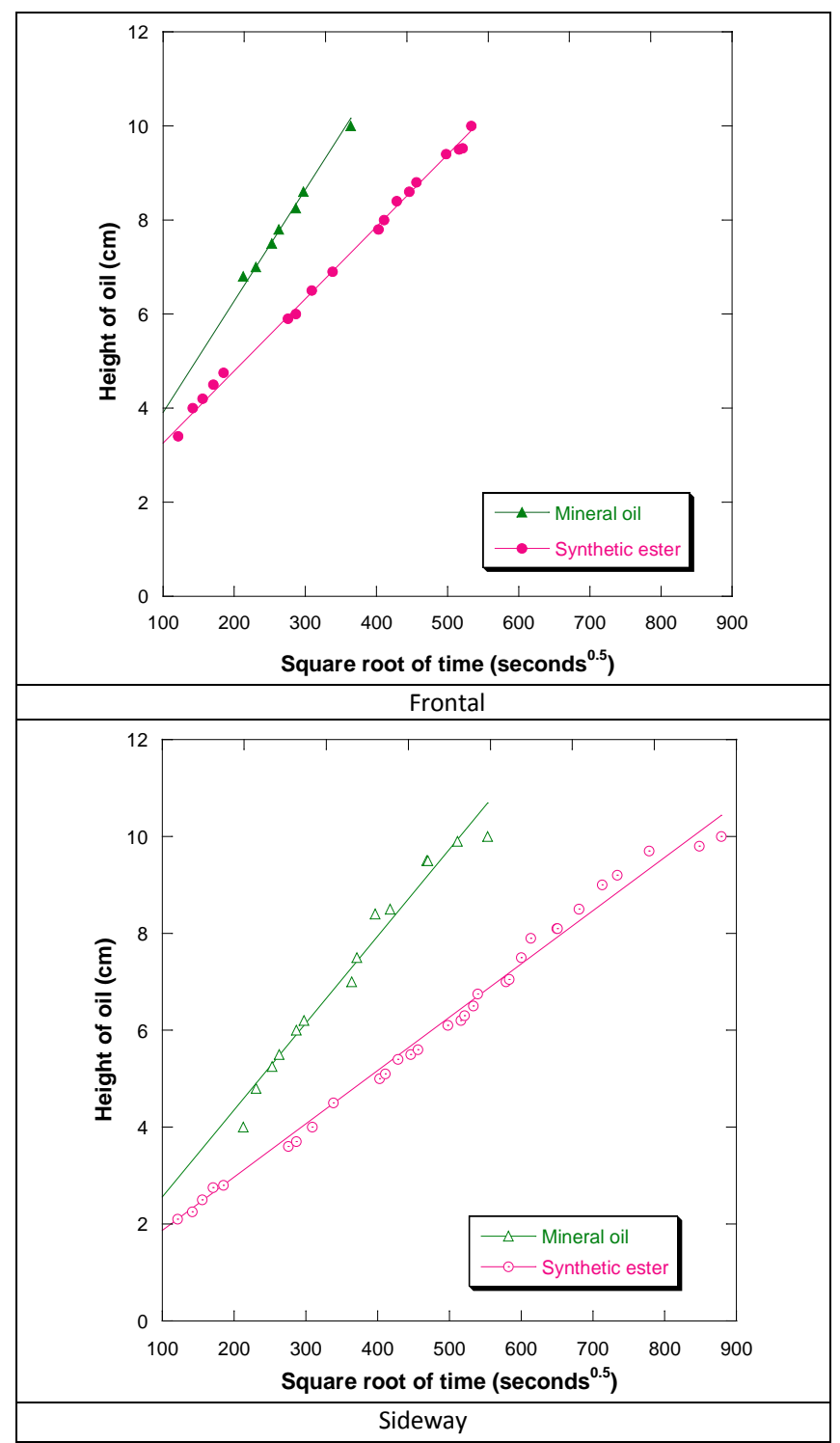

Fig. 3. Impregnation of synthetic ester compared to mineral oil in the laminated pressboard T-IV block.

The analysis of these results allows to establish that the impregnation process in mineral oil is much more sensitive to the type of dielectric rigid material than in the synthetic ester. Considering a period of time of 11 hours, the height differences of the oils in insulation materials during impregnation process have been 1.8, 1.4, 1.75, 3.25, 0.2, 1.6 and 0.5 $\mathrm{cm}$ for the laminated pressboard T-IV block, laminated pressboard T-IV bushing insulation, laminated pressboard TIV sheet (thickness $1 \mathrm{~mm}$ ), laminated press-board T-IV sheet (thickness $2 \mathrm{~mm}$ ), laminated pressboard T-IV spacers, laminated pressboard T-IV strips and phenolic wood block, respectively. In all of them the height of the dielectric fluid is higher in the material immersed in mineral oil. 
TABLE III. SLOPES (CM/ $\sqrt{ }$ SEC) OF OIL HEIGHT VS SQUARE ROOT OF TIME

\begin{tabular}{|l|c|c|c|c|c|}
\hline \multicolumn{1}{|c|}{ Type of insulating rigid component } & & Mineral oil & R & Synthetic ester & \multicolumn{1}{c|}{ R } \\
\hline Laminated pressboard T-IV block & Frontal & 1.7292 & 0.9289 & 1.5326 & 0.9418 \\
\cline { 2 - 6 } & Sideway & 0.7634 & 0.9931 & 0.7582 & 0.9968 \\
\hline Laminated pressboard T-IV bushing insulation & & 1.8348 & 0.9546 & 0.5452 & 0.9982 \\
\hline Laminated pressboard T-IV sheet (thickness 1mm) & & 2.0761 & 0.9955 & 1.6001 & 0.9959 \\
\hline Laminated pressboard T-IV sheet (thickness 2mm) & & 1.2403 & 0.9988 & 0.8140 & 0.9933 \\
\hline Laminated pressboard T-IV spacer & & 1.0440 & 0.9975 & 0.4456 & 0.9972 \\
\hline Laminated pressboard T-IV strips & Frontal & 1.3120 & 0.9978 & 0.7281 & 0.9959 \\
\cline { 2 - 6 } & Sideway & 0.6350 & 0.9939 & 0.0532 & 0.9968 \\
\hline Phenolic wood block & Frontal & 2.9192 & 0.9749 & 1.8334 & 0.9908 \\
\cline { 2 - 6 } & Sideway & 5.1290 & 0.8982 & 3.4661 & 0.9172 \\
\hline
\end{tabular}

\section{CONCLUSIONS}

This paper has studied the effect of a mineral oil and a synthetic ester on the impregnation process of different insulation rigid materials. These experiments were carried out at a high temperature $\left(70^{\circ} \mathrm{C}\right)$.

The experimental results have shown that the impregnation times depend on the kind of dielectric oil and also on the type of insulation rigid material. Furthermore, it has been tested that the impregnation rate suffers higher variation when different rigid materials are immersed in mineral oil. Additionally, it has been found that the phenolic wood block possesses the maximum impregnation rate in both oils in comparison with the rest of materials. On the other hand, the material in which the rate is minimum in the mineral oil is the laminated pressboard T-IV spacers whereas in the synthetic ester is the laminated pressboard T-IV strips. The seven studied materials exhibited a higher impregnation rate in mineral oil.

\section{REFERENCES}

[1] SV. Kulkarni and SA. Khaparde, "Transformer engineering: design and practice”, CRC Press, 2004.

[2] G. Dombek and Z. Nadolny, "Thermal properties of a mixture of synthetic and natural esters in terms of their application in high voltage power transformers”, Eksploatacja i Niezawodnosc - Maintenance and Reliability; vol. 19(1), pp.62-67, 2017.

[3] N. Zhuravleva, A. Reznik, D. Kiesewetter, A. Tukacheva and E. Smirnova, "About the possibilities of increasing the reliability of paper-impregnated insulation of power transformers”, 57th Int. Scient. Conf. Power Electr. Eng. Riga Tech. University (RTUCON), 2016.

[4] X. Wang, C. Tang, B. Huang, J. Hao and G. Chen, "Review of research progress on the electrical properties and modification of mineral insulating oils used in power transformers”, Energies;vol. 11(3), p. 487, 2018.

[5] K. Yoshida, M. Nakamura, Y. Kazue, N. Tachikawa, S. Tsuzuki, S. Seki, K. Dokko and M. Watanabe, "Oxidative-stability enhancement and charge transport mechanism in glyme-lithium salt equimolar complexes”, J. Am. Chem. Soc., vol. 133(33), pp. 13121-13129, 2011.

[6] M. Rafiq, YZ. Lv, Y. Zhou, KB. Maa, W. Wang, CR. Li and Q. Wang, "Use of vegetable oils as transformer oils - a review", Renew. Sustain. Energ. Reviews, vol. 52, pp. 308-324, 2015

[7] K. Bandara, C. Ekanayake and TK. Saha, "Compare the performance of natural ester with synthetic ester as transformer insulating oil”, IEEE 11th Int. Conf. Propert. Applic. Dielectr. Mater. (ICPADM), 2015.

[8] I. Fernández, A. Ortiz, F. Delgado, C. Renedo and S. Pérez, "Comparative evaluation of alternative fluids for power transformers", Electr. Power Syst. Research, vol. 98, pp.58-69, 2013.

[9] SY. Matharage, Q. Liu, ZD. Wang, G. Wilson and C. Krause, “Aging assessment of synthetic ester impregnated thermally non-upgraded kraft paper through chemical markers in oil”, IEEE Trans. Dielectr. Electr. Insul., vol. 25(2), pp.507-515, 2018.
[10] OHA. Fernández, I. Fofana, J. Jalbert, S. Gagnon, E. Rodriguez-Celis, S. Duchesne and M. Ryadi, "Aging characterization of electrical insulation papers impregnated with synthetic ester and mineral oil: Correlations between mechanical properties, depolymerization and some chemical markers”, IEEE Trans. Dielectr. Electr. Insul., vol. 25(1), pp. 217-227, 2018.

[11] C. Thirumurugan, R. Oruganti and GB. Kumbhar, "Investigation of partial discharges in synthetic ester-pressboard under AC stress”, IEEE Int. Power Modulator High Volt. Conf. (IPMHVC), 2016.

[12] A. Beroual, U. Khaled, PSM. Noah and H. Sitorus, "Comparative study of breakdown voltage of mineral, synthetic and natural oils and based mineral oil mixtures under AC and DC voltages”, Energies, vol. 10(4), p. 511, 2017.

[13] TW. Park and SH. Han, "Numerical analysis of local hot-spot temperatures in transformer windings by using alternative dielectric fluids”, Electr. Eng., 97, pp. 261-268, 2015.

[14] LE. Feather, "Drying and oil impregnation of power transformer insulation”, Sixth Electr. Insul. Conf., 1965.

[15] IEC 60270 Standard, "High voltage test techniques. Partial discharge measurements”, 2000.

[16] AU. Dufour and GG. Molinari, “A study of pressboard monodimensional impregnation with transformer oil and its influence on dielectric strength”, IEEE Trans. Electr. Insul, vol. EI-10(4), pp. 135-144, 1975.

[17] T. Suzuki and M. Takagi, "Oil impregnation in transformer boards (1) measurement of impregnation depth and internal pressure”, IEEE Trans. Electr. Insul., vol. EI-19(4), pp. 340-343, 1984.

[18] T. Suzuki and Takagi M, “Oil impregnation in transformer boards (2) theoretical analysis of changes in impregnation depth”, IEEE Trans. Electr. Insul., vol. EI-19(4), pp.344-349, 1984.

[19] C. Krause, W. Goetz and B. Heinrich, "The impact of drying and oil impregnation conditions and of temperature cycles on the clamping force of power transformer windings”, IEEE Int. Symposium Electr. Insul., Boston, MA, USA, 2002.

[20] J. Dai, ZD. Wang, P. Dyer, AW. Darwin and I. James, "Investigation of the impregnation of cellulo-sic insulations by ester fluids", Annual Rep. Conf. Electr. Insul. Dielectr. Phenom. (CEIDP), Vancou-ver, BC, Canada, 2007.

[21] J. Dai and Z. D. Wang, “A comparison of the impregnation of cellulose insulation by ester and mineral oil”, IEEE Trans. Dielectr. Electr. Insul., vol. 15(2), pp. 374-381, 2008.

[22] G. Lu, Q. Huang, H. Song, and P. Wu, “Impregnation model and experimental investigation of vegetable insulating oil-paper insulation”, ICHVE International Conference on High Voltage Engineering, 2014.

[23] C. Krause, "Power transformer insulation - history, technology and design,” IEEE Trans. Dielectr. Electr. Insul., vol. 19(6), pp. 1941-1947, 2012.

[24] K. Ni, H. Fang, Z. Yu, and Z. Fan, "The velocity dependence of viscosity of flowing water,” J. Molecular Liq., vol. 278(15), pp. 234238, 2019.

[25] M. Sophocleous, "Understanding and explaining surface tension and capillarity: an introduction to fundamental physics for water professionals,” Hydrogeology J., vol. 18, pp. 811-821, 2010. 